\title{
Organization of Parental Gender Education in the Military Conflict Zone in Ukraine
}

\author{
Iryna Trubavina ${ }^{1, *}$, Liudmyla Tsybulko², Natalia Mohylyova ${ }^{3}$, Olha Radziyevska $^{4}$ and \\ Yulia Medvid ${ }^{5}$
}

\author{
${ }^{1}$ Department of Social and Humanitarian Disciplines, National Guard of Ukraine National Academy, Kharkiv, Ukraine \\ ${ }^{2}$ Department of Pedagogy, Donbas State Pedagogical University, Sloviansk, Ukraine \\ ${ }^{3}$ Department of Speech Therapy and Special Psychology, Donbas State Pedagogical University, Sloviansk, Ukraine \\ ${ }^{4}$ Foreign Languages Department, Donbas State Pedagogical University, Sloviansk, Ukraine \\ ${ }^{5}$ Scientific-organisation Department, National Guard of Ukraine National Academy, Kharkiv, Ukraine \\ *Corresponding author. Email: trubavina@gmail.com
}

\begin{abstract}
The article is based on experience of a tuition project on gender issues for parents in the region of military conflict in Eastern Ukraine, as well as results of experimental works during its system elaboration. 119 teachers and 145 parents took part in the experiment. The following research methods were applied: theoretical analysis, opinion poll of parents and teachers, a pilot pedagogical experiment and generalization. Main findings were: 1) a set of scientific approaches to the elaboration of tuition system (gender, familycentric, interdisciplinary, systematic, socio-educational, activities-related, androgogical, informational, human rights theory, development theory); 2) content of education on gender issues (initial, secondary, tertiary parental education), themes for parents of children of various age groups; 3) system of education (aimorientated, diagnostic, motivational, prognostic, substantive, operational, control and correction components); 4) conditions for the application of educational system for parents (pedagogical, organizational, methodical). The scientific novelty and originality consist of science-based, differentiated, targeted and multi-level parental education in conditions of military conflict.
\end{abstract}

Keywords: scientific approaches, gender parental education, conditions for introduction of gender parental

education system

\section{INTRODUCTION}

The relevance of the study is related to the fact that: 1) according to the Gender Equality Index, Ukraine ranks 61st in the world according to the UNDP [1], which makes it necessary to find new ways to achieve gender equality in society; 2) existing documents and research mainly deal with legal issues of equal rights for women and men in various spheres of life [2;3], gender analysis of the existing legislation [4]. Although the Council of Europe's Gender Equality Strategy for 2018-2023 [5], which is being implemented in Ukraine, emphasizes intersectoral cooperation in the problem's solution, refers to men as active carriers of gender stereotypes, focuses on the need to work with families based on women's and men's rights. This correlates with our views on the content of parental education in general secondary education and systematic work with families [6], but does not facilitate scientific and methodological organization of such education. 3)Additional risks and dangers for gender-based violence and non-compliance with gender equality exist in the zone of military conflict, so work with the entire population is required to prevent it [7]. 4) Today all schools in Ukraine and their teachers have been tasked by the Ministry of Education and Science to prevent human trafficking (this crime is often a manifestation of gender inequality) and criminal offenses, in particular on the basis of gender inequality. There is no system and experience of such work, as well as recommendations for its implementation with students and their parents. 5) Educational work with parents is carried out only on the basis of voluntary acceptance of social services. Working with a student's family is the responsibility of class teachers, but these opportunities are not involved in shaping the gender culture of adults. Considering the above, the implementation of a well-grounded parental gender education system in a general secondary educational institution in cooperation with community social workers has significant potential in shaping the gender culture of adults and their children.

Existing theoretical research and experience in the problem's solution. The existing research shows that school influences parents in the direction of expanding or narrowing their choices about the quality of children's education, promote their upbringing, forms a new life experience [8]. There is, therefore, a chance for the formation of a gender culture by parents and then through 
them by their children. At the same time, there is a different interest in the interaction of parents and school depending on the gender of students' parents, respectively, different incentives are needed for parents to participate in the education of their children [9]. O. Kikeneji's research dealt with gender psychology and pedagogy in relation to children [10]. It regarded the consequences of gender inequality among pre-schoolers, arguing that the problem is relevant and requires prevention which is possible through schools. V. Kravets studied the issues of sexual pedagogy, preparation of schoolchildren for family life, gender pedagogy [11]. Those studies were not multidisciplinary and were focused on children and young people, not their parents. But they show non-juridical ways to approach the issues in the secondary education system. The existing researches relate to the problems of gender education of boys and girls in the family, self-education of parents on these issues, as well as conditions that facilitate parental education: national mentality, level of parents' education, gap in education of mothers and fathers, availability of openness in family communication, systematic work on violence prevention, parental participation in education $[6$, $12,13,14,15,16]$. The currently ongoing anti-violence projects "Polina" by the Ministry of Internal Affairs of Ukraine and other ones, based on multidisciplinary work with domestic violence, prove their effectiveness in terms of multidisciplinarity, but they work on the fact of violence, without subsequent education. The experience of the multidisciplinary team in Ukraine also covers combating child abuse, work of territorial centres of the Ministry of Social Policy with single elderly people, social support of families by a team of social workers in centres of social services for families, children and youth (case management 3 and 4 levels), there is an attempt to create such system of children protection (initiative of the ombudsman for protection of children's rights M. Kuleba). However, the education system remains separate from multidisciplinary work. We have a separate positive experience of creating a school social psychological-pedagogical service in Kharkiv [14]. Parental education was considered by us as a 3 levelssystem in preschool institutions [6]. The peculiarities of socio-pedagogical and psychological work at education institutions in the condition of a military conflict are that a school becomes the centre of a community, all assistance to the population is provided there [7]. Our assumption is that the solution to the problem of setting-up parental gender education is possible through scientifically grounded multidisciplinary and interagency work in an institution of general secondary education in the area of military conflict. Objective and tasks of the article. The purpose of the article is to develop a system of gender parental education, its implementation in school practice. The objectives of the article are: 1) substantiation of the theoretical foundations of gender parental education in an institution of general secondary education in the zone of military conflict; 2) identification of such education system and its components; 3) definition and generalization of conditions for introduction of such education system.
Our contribution. The scientific novelty and originality lie in the substantiation and experimental verification of the mass parental gender education system in a general secondary education institution in the zone of military conflict.

Research methods, materials and methodology research. The research methods were a theoretical analysis of the sources, generalization of school practice, modelling, surveys and a pilot pedagogical experiment. Two schools with 119 pedagogical workers altogether were selected for the survey - in the village of Bylbasivka and №13 in Slovyansk, both in Donetska oblast, the region with a military conflict. The experimental work was carried out in 2019-2020. The following materials were selected: 1) the current legislation of Ukraine on gender equality; 2) the normative documents about interaction of social and educational institutions in counteraction to gender-related violence. 3) the research on gender approach to life, the theory of gender in education $[18,19,20,21]$; 4) the research of parental education [6]; 4) the results of the school teachers (119) and students' parents (145) surveys. Stages of the research. The project was implemented by us in several phases. The first one dealt with definition and substantiation of the work's theoretical foundations, clarification of the needs and wishes of project's participants; the second phase was related to elaboration on this basis of a parental gender education system in a general secondary education institution; the third one was about conducting a pilot pedagogical experiment and determining the various conditions for the success of such education.

\section{RESULTS OF THE RESEARCH}

\subsection{Substantiation of Technology and Conditions for Organization of Parental Gender Education}

We understand parental education in a general secondary education institution as a direction of domestic violence prevention, introduction of gender equality in life of every family. Considering gender, family-centric, informational approaches, the human rights theory and human rights approaches, we believe that family members should be aware of their rights and be able to exercise them while respecting the rights of others. Therefore, gender education can be implemented in a secondary education institution as informative, individual and corrective work, aimed to change attitudes to the issue, consolidating its awareness, social education, etc. An educational institution can cooperate with social services of a community and carry out social education in it together, facilitating application of interdisciplinary, family-centric, socio-educational approaches to gender education of students' parents. The family-centric approach allows providing guidelines for the activities of all subjects of work with the family. The 
subjects of education are all pedagogical workers of the educational institution and social workers of a community. Therefore, gender, interdisciplinary, socio-educational, informational, family-centered approaches, the human rights theory, the development theory, interdepartmental, interdisciplinary scientific approaches are the theoretical basis of the gender parental system in the system of general secondary education. A special place in the system of parental gender education belongs to the androgynous approach which requires to take into account the experience of adults while implementing educational efforts. The problem of ensuring gender equality in the family is: a) socio-pedagogical (positive model of building family relations); b) psychological (in the context of family members' attitude to the problem); c) pedagogical (in the aspect of gender education); d) interdisciplinary; d) legal, as gender equality is regulated by law. Thus, the system of gender parental education should be both interdisciplinary and specialized, embracing all employees. Therefore, it is possible to speak affirmatively about the general and special purpose, the content, forms, methods of experts' educational work. The systemic factor in education should be the common goal - to create a variety of conditions for the formation of parents' gender culture.

The work system consists of the components that ensure its implementation: 1.The target component. Includes the goal - to create social, psychological, pedagogical conditions in an institution of general secondary education in order to ensure gender equality in a family, educational institution, micro-environment, community. 2.The diagnostic component. It requires identification of parents' attitude to gender equality and their needs in such education, as well as clarification of difficulties for teachers in its implementation. The consequence of the diagnosis is differentiation of parents by groups for the organization of initial, secondary and tertiary preventive work. 3.The motivational component. It involves formation of parents and teachers' positive motivation to implement the ideas of gender equality in everyday life and encourage them to adhere to them. Motivation is offered via social advertising, demonstrating consequences of gender inequality and benefits of gender equality. Incentives are appropriate for identification of violence cases, including negative attitudes of parents to gender equality, manifestation of gender stereotypes, etc. When stimulating, pedagogical and social workers offer joint social support (case management of levels 3 and 4) and an agreement on the conditions of service. 4 . The prognostic component of the system means planning the results of the work, its volume, timing and content, forms of work. It is necessary to plan the work of an educational institution according to class teachers' work plans, school educational work plan, school academic year plan of work, as well as define joint and separate actions of pedagogical workers, their interaction with social workers. 5. The content component of the system assumes definition of gender education aspects in the work of each pedagogical worker. Such work can be carried out on the basis of, 1) joint types of work: preparation of children and youth for family life, formation of parental competence and conscious, responsible parenting, social rehabilitation, social support, primary social prevention; 2) certain types of work: psychological work with children and their parents (diagnostics, individual and correctional work); work of the administration of an educational institution with parentsactivists, educational work of class teachers on formation of gender equality among students of different ages, sociopedagogical work: social patronage of students in difficult life circumstances, social inspection of families, work of parent universities and clubs, secondary and tertiary social prevention (with risk groups and those who already experience gender inequality in their families), etc. Gender education of different levels: primary, secondary, tertiary prevention. 6. The operational component involves the selection of those technologies, forms and methods of work that implement the above mentioned scientific approaches. These include: peer-to-peer technology, facilitation, selfeducation, counselling, informing, persuasion, exercises, and more. The training is experience-based, work is structured for a specific case, the main forms of work are trainings, lectures, parents' clubs, parents' universities, panel discussions, etc. Case management is done jointly with social workers. 7. The control and correction component assumes visits to families by a class teacher with three parents-activists of the same class, and in case of suspected or detected domestic violence - social inspection of a family together with a district police inspector and representative of social services, diagnosis of family life, conditions for the development and education of the child. On the basis of control correction of education is possible: in case of successful parents' education and change of behaviour they are offered to pass to the next level of education.

\subsection{Experimental Work}

The proposed system of work was proved at pedagogical councils in experimental educational institutions, approved by the teams of their pedagogical workers, was contributed with methodological recommendations on the problem for teachers, for planning and conducting parent meetings as the most widespread form of parental education [21]. The decisions of pedagogical councils were made due to the need for such work, for preparation of teachers to do it with parents, for the development of school plans on the problem, orders for the implementation of the work system. A survey of the teachers on gender training needs was conducted. All respondents (119 teachers) noted the need for methodological materials on gender education of parents, the system of training lessons, special preparation for such work, noted partial experience in the problem. We diagnosed parents' attitudes towards gender equality and the need for parental gender education through an anonymous questionnaire (145 parents) (Table 1). The results of the survey are reflected in table 1, where A in 1-3 questions is "Yes", B in 1-3 questions is "No", $\mathrm{C}$ in 1-3 questions is "In part", A in question 4 is "Positive", B is "Negative", C is "Hard to say". 1 is the questionnaire at the 
beginning of the experiment, 2 is the result of the final stage of the experiment.

At the same time, there was an acquaintance of pedagogical and social workers among themselves, formation of intentions about joint actions, revealing of parents needs in such education, relation of pedagogical workers to the problem.

Table 1 The results of the parents' survey on the need for parental education

\begin{tabular}{|c|c|c|c|c|c|}
\hline \multirow{2}{*}{ № } & \multirow[t]{2}{*}{ Questions } & Answers A & Answers B & \multicolumn{2}{|c|}{ Answers C } \\
\hline & & $1 \quad 2$ & $1 \quad 2$ & 1 & 2 \\
\hline 1 & $\begin{array}{l}\text { Do you carry out gender } \\
\text { education of your children? }\end{array}$ & $\begin{array}{l}143 / \\
98.6 \%\end{array}$ & $\begin{array}{c}0 / \\
0 \%\end{array}$ & $\begin{array}{l}25 / \\
17.2 \%\end{array}$ & $\begin{array}{c}2 / \\
1.4 \%\end{array}$ \\
\hline 2 & $\begin{array}{l}\text { Do you need gender } \\
\text { education in the upbringing } \\
\text { and education of boys and } \\
\text { girls? }\end{array}$ & $\begin{array}{cc}130 / & 145 / \\
89.6 \% & 100 \%\end{array}$ & $\begin{array}{l}0 / \\
0 \%\end{array}$ & $\begin{array}{c}15 / \\
10.3 \%\end{array}$ & $\begin{array}{c}0 / \\
0 \%\end{array}$ \\
\hline 3 & $\begin{array}{l}\text { Do you have gender } \\
\text { equality in your family? }\end{array}$ & $\begin{array}{cc}43 / & 85 / \\
29.6 \% & 58.6 \%\end{array}$ & $\begin{array}{l}0 / \\
0 \%\end{array}$ & $\begin{array}{l}102 / \\
70.3 \%\end{array}$ & $\begin{array}{r}60 / \\
41.4 \%\end{array}$ \\
\hline 4 & $\begin{array}{l}\text { What is your attitude } \\
\text { towards gender equality in } \\
\text { the family? }\end{array}$ & $\begin{array}{cc}45 / & 89 / \\
31 \% & 61.4 \%\end{array}$ & $\begin{array}{cc}14 / & 7 / \\
9.7 \% & 4.8 \%\end{array}$ & $\begin{array}{l}86 / \\
59.3 \%\end{array}$ & $\begin{array}{c}49 / \\
33.8 \%\end{array}$ \\
\hline
\end{tabular}

Social workers were invited to pedagogical councils of schools; they were instructed about their tasks, functions, specific goals and activities. Thus the subject and the plan of educational work were formed. All pedagogical workers understood the necessity of the work; none were unwilling to work with parents. The training of pedagogical workers was carried out by reading methodological literature, seminars, meetings of methodological associations, lectures at pedagogical councils with the teachers of Donbass State Pedagogical University (DSPU). Topics of the lectures were the following: "Gender equality in the family and the Ukrainian mentality", "Gender culture of parents - what it manifests itself in", "Communication of parents on the basis of gender equality", "Choosing a child's profession on the basis of gender equality", "Violence in phase of teenage dates", "Teaching children critical thinking and protection from manipulations", "Domestic violence - how to protect yourself", "Military conflict and the risks of community violence", etc. The students who had internships in these schools and the authors of the article were involved in conducting classes with the pedagogical workers. There were question-andanswer meetings, panel discussions, and conversations on the issue. In educational institutions, gradually, over the course of six months, together with the teachers of DSPU, the topics of lectures on the problem for meetings with parents were being compiled and discussed. It was the primary mass education of parents (primary prevention) on the issues that interested most of the parents. Those were the following topics [21]: 1) Primary school: "How to raise a boy and a girl in the family: is there a difference?", "How to prepare a girl and a boy for school?", "How and what to teach a boy and a girl?", "How to communicate without domestic violence?", "How to make family decisions and raise children on the basis of gender equality?". 2) Secondary school: "How to communicate with friends of a boy and a girl at home?", "How to organize homework and self-care for a boy and a girl?", "Which parent should talk to the children about puberty and sex education in the family and how should it be done?", "How to express marital feelings in children's presence?", "How to help a child in sexual socialization?". 3) Vocational school: "How to help a child choose a profession basing on gender equality", "How to talk to children about love on the basis of gender equality", "Gender culture in relationships between family members: how it is manifested and how it is formed", "How to form life prospects and goals for a boy and a girl?"

Secondary prevention was carried out in a differentiated way. The topics of correctional classes were offered to the parents from families in difficult circumstances where there were conditions for violence. This was arranged in cooperation with social workers of the communities according to the plan of social support (case management of the 3rd level of complexity). The work lasted for a year, as much more efforts were needed for problematic families. There were five such families, they are registered in the centre of social services for families, children and youth. The correctional work has been carried out according to the correctional program for domestic abusers. This programme was standardized for the whole country. The tertiary prevention in education was carried out as individual work with families where violence had been detected, there were two such families. Here the work started from overcoming the crisis of the family up to its functioning and development with the help of various sets of social services and parental education in the specific area of violence. We chose two programs for the work: 1) for children who are difficult to raise and 2) for parents who had aggression [22]. Confidential pedagogical consultations were organised, the work was combined with the management of level 4 complexity case by social services. A joint action plan for services and schools with each family was developed and the children were registered in the schools to work with them. 
Based on the study of the experience of parental education in practice and the experiment, we can identify the conditions for implementing the system of gender education of parents in an education institution: 1) pedagogical conditions: gender equality environment, professional readiness to work with parents, knowledge of families' pedagogical characteristics, ability to diagnose attitudes of children and their parents to gender equality, to describe it; 2) organizational conditions: organization of interaction between an educational institution and social services of a district; availability of pedagogical management of problem solving in an education institution; defined gender educational component of work in the job responsibilities of each pedagogical employee; availability of different levels work plans on the problem. 3) methodological conditions: availability of methodological support for solving the problem, knowledge and adherence to special ethics of work with the family by teachers.

\subsection{Discussion of Results}

The conducted work showed that gender education of parents is efficient if the set of conditions for its realization is fulfilled on a theoretical basis in combination with the system of its realization. The most important thing was to prepare teachers for the project, to encourage parents to participate in it. The teachers were interested in how to behave on the basis of gender equality. Interesting were the portraits of family abusers, methods of family communication and raising children in a family without violence. All interested parents were invited to apply to social services to participate in parent schools, clubs, universities. Parents' meetings and educational activities of the school were organised during non-working hours, but not everyone was able to get there. The study identified several pressing issues that need to be solved at the level of the Ministry of Education: introduction of the "Gender Studies" discipline as a mandatory one integrated into the curriculum of pedagogical education institutions; at the level of an institution of pedagogical education it should be the "Gender Pedagogy" discipline as selective one at the choice of the university; "Gender Psychology" and "Gender Education in the Family" disciplines can be done at the choice of students. The question arises about the need for compulsory parental education in the draft of "Law on Adult Education". There is a need to improve the skills of teachers in gender education and parental education.

\section{CONCLUSION}

We proved the possibility of implementing parental gender education in a general secondary education institution on the basis of a set of scientific approaches: gender, familycentric, androgynous, socio-educational, interdisciplinary, interdepartmental, activity, systemic, informational, human rights theory, development theory, human rights approaches. Such a system includes target, diagnostic, motivational, prognostic, semantic, operational, control and correction components. The system-forming factor is the goal. The complex of conditions for such education system implementation in an educational institution is defined: pedagogical, organizational, methodical. The prospects for further research of the problem are: professional training and retraining of teachers for such work, development of the education digital forms under COVID-19 quarantine conditions, etc.

\section{REFERENCES}

[1] United Nations Development Programme: The Gender Inequality Index 2019 [URL:

https:/gtmarket.ru/ratings/gender-equity-index-un/info]

[2] I. Rabotina, "Research of gender equality in Ukraine," 2017 [URL: https://platformamsb.org/doslidzhennya-gendernoyi-rivnosti-v-ukrayini/] [in Ukrainian]

[3] J. Wrigley, "Education and Gender Equality," American Journal of Education 102, 3 (1992). DOI https://doi.org/10.1086/444076

[4] Every law is an opportunity to reduce inequalities between men and women (2017). [URL: https://www.ua.undp.org/content/ukraine/en/home/ourp erspective/ourperspectivearticles/2017/10/04/every-lawis-an-opportunity-to-reduce-inequalities-between-menand-women-.html]

[5] Gender strategy equalities of the council of Europe for 2018-2023 (2018) 57 p. [URL: https://rm.coe.int/prems-041318-gbr-gender-equalitystrategy-2023-ukr-new2/16808b35a4]

[6] I. Trubavina, "Parental education in modern preschool educational institutions of Ukraine," Pedagogical sciences: theory, history, innovative technologies 6 (2016). pp. 189-198 [URL: http://nbuv.gov.ua/UJRN/pednauk_2016_6_21] [in Ukrainian]

[7] K. Levchenko, V. Panok, I.Trubavina(Eds.), "Peacebuilding conflict prevention and resolution with the use of mediation: socio-pedagogical aspect," Kyiv (2016), 192 p. [in Ukrainian]

[8] H. Beal, P. Hendry, "The Ironies of School Choice: Empowering Parents and Reconceptualizing Public Education," American Journal of Education 118, 4 (2012). DOI: https://doi.org/10.1086/666360 
[9] S. Eng, W.Szmodis, M. Mulsow, "Cambodian Parental Involvement: The Role of Parental Beliefs, Social Networks, and Trust," The Elementary School Journal 114, 4 (2014). DOI:

https://doi.org/10.1086/675639

[10] I. Shulga, O. Kikinezhdi, T. Govorun, “Gender education of preschool children," Textbook (2015) 192 p. [in Ukrainian]

[11] V. Kravec "Preparing students to perform parental functions: foreign experience," Pedagogical Almanac, 40 (2018) pp. 10-18 [in Ukrainian]

[12] A. Pugh, "The Gender Trap: Parents and the Pitfalls of Raising Boys and Girls," American Journal of Sociology 119, 6 (2014). DOI: https://doi.org/10.1086/676323

[13] S. Eng, W.Szmodis, M. Mulsow, "Cambodian Parental Involvement: The Role of Parental Beliefs, Social Networks, and Trust," The Elementary School Journal 114, 4 (2014). DOI: https://doi.org/10.1086/675639

[14] O. Kolesnikova, "Organizational and pedagogical bases of activity of social psychological and pedagogical service in comprehensive school," Author's dissertation, Poltava (2011) 20 p. [in Ukrainian]

[15] A. McDaniel, "Cross National Gender Gaps in Educational Expectations: The Influence of National Level Gender Ideology and Educational Systems," Comparative Education Review 54, 1 (2010). DOI: https://doi.org/10.1086/648060

[16] E. Pérez, M. Tavits, "Language Influences Public Attitudes toward Gender Equality," The Journal of Politics 81, 1 (2019). DOI: https://doi.org/10.1086/700004
[17] A. Tansel, "Schooling Attainment, Parental Education, and Gender in Côte d'Ivoire and Ghana," Economic Development and Cultural Change 745, 4 (1997). DOI: https://doi.org/10.1086/452309

[18] T. Isayeva: "Politics with a human face is a gender approach," Public space (2019) [URL:

https://www.prostir.ua/?focus=tetyana-isajeva-politykaz-lyudskym-oblychchyam-tse-i-je-hendernyj-pidhid] [in Ukrainian]

[19] O. Tsokur, I. Ivanova, Development of a gender approach in education [URL: http://osvita.ua/school/ technol / 313] [in Ukrainian]

[20] Domestic Violence Perpetrator Programs in Europe, Part I: A survey of Current Practice, International Journal of Offender Therapy and Comparative Criminology 10 (2012)

[21] Countering bullying at school [URL: http://slovschool13.com.ua/index.php/pro-zakladosviti/pravila-dlya uchniv.html\#https://drive.google.com/file/d/1RbzVzP8fkQ8J-bno856I2x-iCopR290/view?usp=sharing]; To help teachers in formation of gender equality and counteraction to violence: methodical recommendations, compilers: I. Trubavina, L. Tsybulko, N. Mogilev, O. Radzievskaya

[URL:https://drive.google.com/file/d/1T9Asmgbjk27h6 nFDzDcLIf2meClHwcsk/view] [in Ukrainian]

[22] Social and correctional work with persons who have committed domestic violence: a textbook in 2 vols. Vol. 2 / edited by O. Bandurka, K. Levchenko, I. Trubavina, Kyiv- Kharkiv: Ukraine (2014) 204 p. [in Ukrainian] 